\section{Single mesodermal cells guide outgrowth of ectodermal tubular structures in Drosophila}

\author{
Christian Wolf and Reinhard Schuh ${ }^{1}$ \\ Max Planck Institut für biophysikalische Chemie, Abteilung \\ Molekulare Entwicklungsbiologie, Am Fassberg, D-37077 \\ Göttingen, Germany
}

The Drosophila tracheal system, a tubular network, is formed from isolated ectodermal metameres by guided branch outgrowth and branch fusion. Branch outgrowth is triggered by the localized and transient activity of Branchless (Bnl/dFGF). Here, we report the discovery of a mesodermal cell that links the leading cells of outgrowing main branches $2.5 \mathrm{hr}$ before they fuse. This bridge-cell serves as an essential guidance post and needs Hunchback $(\mathrm{Hb})$ activity to exert its function. The bridge-cell provides cues acting in concert with $\mathrm{Bnl} /$ dFGF signaling to mediate directed branch outgrowth that ultimately leads to position-specific branch fusion.

Received May 16, 2000; revised version accepted July 5, 2000.

Formation of three-dimensional tubular structures, such as the insect tracheal system (Manning and Krasnow 1993; Samakovlis et al. 1996), the vertebrate vascular system (Risau 1997), and the lung (Hogan et al. 1997), involves the guided outgrowth of epithelial cells. In Drosophila, the tracheal system is generated from 10 isolated lateral cell clusters on each side of the embryo (Fig. 1A). These cell clusters, which are each composed of about 80 ectodermal cells, invaginate in a strictly coordinated manner into the underlying mesoderm, where they establish a pattern of six primary tubular branches (Fig. 1B). Some of these branches grow along the dorsoventral body axis to form the dorsal, the lateral, and the ganglionic branches. Additional primary branches extend along the anteroposterior axis to generate the visceral and dorsal trunk anterior and posterior branches. The individual tracheal cell clusters connect by fusion of the dorsal trunk and the lateral trunk branches (Fig. 1C). The two halves of the network interconnect by anastomosis formation, and the three-dimensional system starts with the transport of gases during larval development (for details, see Manning and Krasnow 1993; Samakovlis et al. 1996).

Tubular branch outgrowth is guided by the local and complex expression pattern of a Drosophila FGF homo$\log$, Branchless (Bnl/dFGF), emanating from cell clusters

[Key Words: hunchback; FGF; tracheal system; Drosophila; guidance] ${ }^{1}$ Corresponding author.

E-MAIL rschuh@gwdg.de; FAX 49-551-201-1755.

Article and publication are at www.genesdev.org/cgi/doi/10.1101/ gad.180900. surrounding each tracheal metamere (Sutherland et al. 1996; Metzger and Krasnow 1999). However, although mutant analysis shows that Bnl/dFGF is necessary for primary branch outgrowth, the restricted Bnl/dFGF expression seems not to be essential for the directed outgrowth of all primary branches. This conclusion is based on the observation that the constitutive activation of $\mathrm{Bnl} / \mathrm{dFGF}$ signaling in bnl mutant embryos partially restores outgrowth of the main tracheal tube, the dorsal trunk, whereas the other primary branches are not generated. Thus, it was proposed that additional guidance cues might be necessary for the outgrowth of dorsal trunk branches (Sutherland et al. 1996).

\section{Results and Discussion}

We noted a single cell that is marked by expression of the gene hunchback (hb; Lehmann 1985; Tautz et al. 1987; Hülskamp 1991) at the posterior lateral margin of each tracheal metamere (Fig. 1D,I). This cell gives rise to daughter cells that maintain $h b$ expression (Fig. 1E,J,K). The more ventrally located daughter cell maintains a round morphology and remains in position, whereas the dorsal daughter cell connects to the posterior bud of the tracheal metamere, termed the dorsal trunk posterior branch (Fig. 1E). Subsequently, the dorsal daughter cell elongates and extends posteriorly and thereby contacts to the anterior bud, termed the dorsal trunk anterior branch, of the adjacent posterior tracheal metamere (Fig. $1 \mathrm{E}, \mathrm{F})$. In this way, the dorsal daughter cell bridges the leading cells of the dorsal trunk anterior and posterior branches of two adjacent metameres (Fig. 1F), which then fuse about $2.5 \mathrm{hr}$ later to form the continuous dorsal trunk. Thus, we refer to the dorsal daughter cell as the bridge-cell. The cell remains at this position until fusion between the dorsal trunk anterior and posterior branches occurs (Fig. 1G). During this fusion process, the bridgecell becomes displaced and $h b$ expression starts to fade (Fig. 1H).

To trace the origin of the bridge-cell, we performed double-staining experiments with tracheal-specific markers and $h b . \beta$-Galactosidase expression in nuclei of dorsal trunk fusion cells and in nuclei of tracheal cells revealed a lack of colocalization with bridge-cell $h b$ expression (Fig. 1L-1O). Furthermore, trachealess (trh; Isaac and Andrew 1996; Wilk et al. 1996) mutant embryos, which lack tracheal cell identity, show $h b$-expressing bridge-cells as found in wild-type embryos (Fig. $1 \mathrm{P}, \mathrm{Q})$. Thus, these results indicate that the bridge-cell is of nontracheal origin. Finally, double-staining of $h b$ and a mesodermal marker (Greig and Akam 1993) revealed coexpression of $h b$ and the marker in bridge-cell precursors (Fig. 1R,S). Therefore, the bridge-cell is a nontracheal cell and of mesodermal origin.

To understand the function of bridge-cells in dorsal trunk formation, we first asked whether bridge-cell development is affected in $h b$ mutant embryos. Homozygous $h b^{F B}$ mutant embryos, which express a nonfunc- 


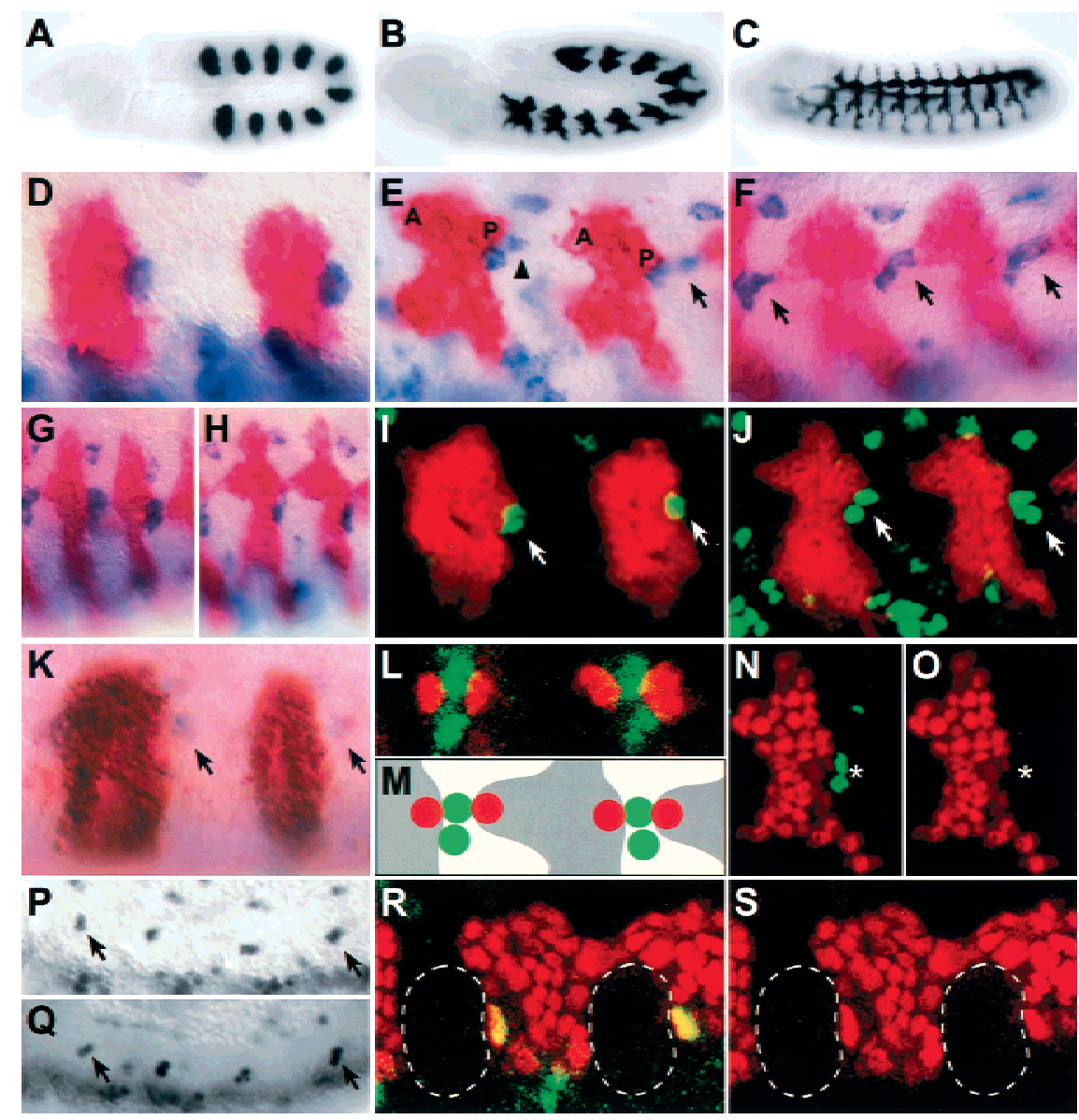

Figure 1. A non-tracheal mesodermal cell connects outgrowing tracheal dorsal trunk branches 2.5 hr prior to their fusion. $(A-C)$ Whole-mount in situ hybridization of 1 -eve- 1 embryos at stage $11(A)$, stage $12(B)$, and stage $13(C)$ with a lacZ antisense RNA probe. 1 -eve-1 embryos reveal lacZ marker gene expression in the tracheal cells. $(D-H)$ Whole-mount in situ double hybridization of 1 -eve-1 embryos at stage $11(D)$, early stage $12(E)$, late stage $12(F)$, stage $13(G)$, and stage $14(H)$ with lacZ (red) and $h b$ (blue) antisense RNA probes; lateral view focusing on tracheal metameres 2 and 3. Arrowhead in $E$ points to a bridge-cell before and arrows in $E$ and $F$ point to bridge-cells after connection to dorsal trunk anterior branches. (A) Dorsal trunk anterior branch; (P) dorsal trunk posterior branch. $(I, J)$ Whole-mount antibody double staining of 1 -eve-1 embryos at stage $11(I)$ and stage $12(J)$ with anti- $\beta$-galactosidase antibodies (red) and anti-Hb antibodies (green). The nuclear stainings with anti-Hb antibodies reveal a single nucleus at stage 11 (arrows in $I$ ) and two nuclei at stage 12 (arrows in $/$ ) posterior to the adjacent tracheal metameres. (K) Whole-mount in situ double hybridization of 1 -eve-1 embryos at stage 11 with lacZ (red) and string (blue) antisense RNA probes. string (stg) expression (arrows), a marker for cell proliferation (Edgar and O'Farrell 1990), corresponds to the localization of the Hb-expressing nuclei (see $I$ ). $(L)$ Whole-mount antibody double staining of stage 13 embryos bearing esg-lacZ with anti- $\beta$-galactosidase antibodies (red) and anti-Hb antibodies (green). The esg-lacZ enhancer trap line was used to mark the dorsal trunk fusion cell nuclei by $\beta$-galactosidase expression (Whiteley et al. 1992). Merged images of red and green pattern reveal no co-expression of $\beta$-galactosidase and $\mathrm{Hb}$. $(M)$ Scheme of tracheal branch formation (grey) and the localization of dorsal trunk fusion cell nuclei (red) and Hb-expressing nuclei (green) at stage 13 . ( $N, O$ ) Whole-mount antibody double staining of stage 12 embryos bearing UAS-GFPNlacZ and btl-Gal4 with anti- $\beta$-galactosidase antibodies (red) and anti-Hb antibodies (green). Merged images $(N)$ of $\beta$-galactosidase expression in the tracheal cell nuclei (red) and nuclear $\mathrm{Hb}$ expression (green) as well as single-channel image for $\beta$-galactosidase expression $(O$; asterisks indicate $\mathrm{Hb}$ expression) reveals no co-expression of $\beta$-galactosidase and $\mathrm{Hb} .(P, Q)$ Antibody staining of a stage 11 wild-type $(P)$ and a trh mutant $(Q)$ embryo with anti-Hb antibodies. (Arrows) Bridge-cell precursors that correspond to tracheal metameres 1 and 4 . $(R, S)$ Whole-mount antibody double staining of stage 11 embryos bearing UAS-GFPNlacZ and twi-Gal4 with anti- $\beta$-galactosidase antibodies (red) and anti-Hb antibodies (green). (R) Merged images of nuclear $\beta$-galactosidase (red) and $\mathrm{Hb}$ expression (green) reveal co-expression of $\mathrm{Hb}$ and $\beta$-galactosidase (yellow) showing $\mathrm{Hb}$ expression in mesodermal cells. (S) Single channel image for $t w i$-driven $\beta$-galactosidase expression in mesodermal cell nuclei (red); broken lines indicate tracheal placodes.

tional $\mathrm{Hb}$ protein because of a premature stop codon mutation (Hülskamp 1991), express the $h b$ transcript only transiently in bridge-cell precursors (not shown), raising the possibility that these cells may die. In fact, TUNEL staining suggests cell death is occurring at positions that correspond to those of bridge-cell precursors in $h b^{F B} \mathrm{mu}$ tants but not in wild-type embryos (Fig. 2A-D). This finding implies that the lack of $h b$ activity causes bridgecell precursors to undergo apoptosis. To show apoptosis as the underlying event of transient $h b$ expression in 

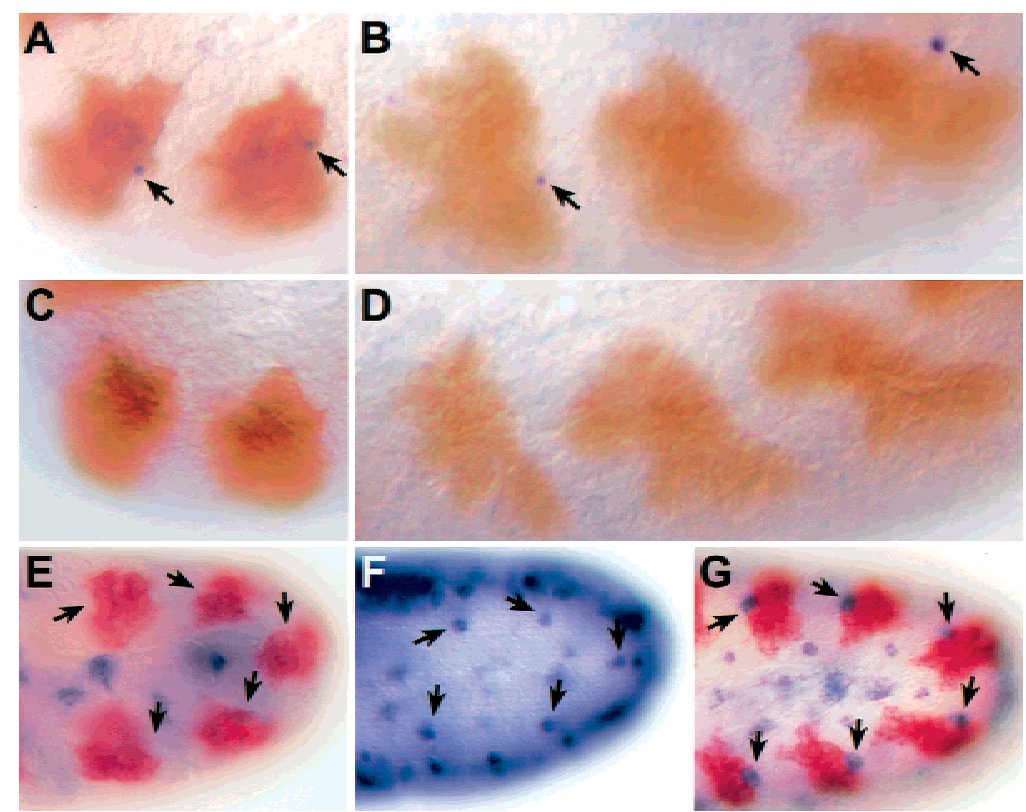

Figure 2. $h b$ mutant embryos reveal apoptosis of the bridge-cell. $(A-D)$ Whole-mount staining with anti- $\beta$-galactosidase antibody (brown) and TUNEL (blue) analysis of late stage $11(A, C)$ and early stage $12(B, D) h b^{F B}$ mutant $(A, B)$ and wild-type $(C, D)$ embryos bearing the 1-eve-1 chromosome. Apoptotic nuclei are detectable in $h b^{F B}$ mutant embryos at posterior lateral positions of the tracheal placodes (arrows in $A$ and $B$ ) but not in wild-type embryos $(C, D)$. $(E)$ Whole-mount in situ double hybridization of a stage $12 \mathrm{hb} \mathrm{b}^{F B}$ mutant embryo bearing the 1-eve-1 chromosome with lacZ (red) and $h b$ (blue) antisense RNA probes. No $h b$ expression is detectable at the expected positions of the bridgecells (arrows in $E$ ). (F) Whole-mount in situ hybridization of a stage $12 h b^{F B}$ mutant embryo bearing actin-Gal4 and UAS-P35 with a $h b$ antisense RNA probe. $h b$ expression is detectable in corresponding cells (arrows in F) after suppression of apoptosis by ubiquitous expression of P35 protein (Hay et al. 1994). (G) Whole-mount in situ double hybridization of a stage 12 wild-type embryo bearing the 1 -eve-1 chromosome with lac $Z$ (red) and $h b$ (blue) antisense RNA probes. $h b$ expression is detectable in the bridge-cells (arrows in $G$ ).

bridge-cells more directly, we ubiquitously expressed in $h b^{F B}$ mutant embryos the baculovirus P35 protein, a suppresser of apoptosis in Drosophila (Hay et al. 1994). In contrast with $h b^{F B}$ mutants, which lack $h b$ expression in the bridge-cells at stage 12 (Fig. $2 \mathrm{E}$ ), $h b^{F B}$ embryos expressing P35 protein maintain $h b$ expression in bridge-cells (Fig. 2F) as is found in wild-type embryos (Fig. 2G). Thus, expression of $h b$ serves as a marker for bridge-cells, whereas its product, a transcription factor (Tautz et al. 1987; Hoch et al. 1991), is essential for bridge-cells viability. Therefore, analysis of tracheal development in $h b^{F B}$ mutant embryos would allow us to study bridge-cell function in dorsal trunk formation directly.

In $h b^{F B}$ mutant embryos initial tracheal development, including primary branch outgrowth, appears normal up to the end of stage 12 (Fig. 3A-D). Subsequently, the dorsal trunk branches become stalled and misrouted, whereas the other primary branches are formed as in wild-type embryos (Fig. 3E-H). Despite the strong dorsal trunk phenotype, the dorsal trunk branches occasionally fuse in $h b^{F B}$ mutant embryos and form dorsal trunk ru- diments (Fig. 3F,H). This observation and normal expression of the escargot (esg) fusion cell marker (Whiteley et al. 1992) in $h b^{F B}$ mutant embryos (Fig. 3I) suggest that the fusion process, required for dorsal trunk formation, is not impaired in $h b^{F B}$ mutant embryos. These results indicate that $h b$ is not necessary for the initial outgrowth but for the subsequent outgrowth of dorsal trunk branches. Thus, the results also suggest that the $h b$-dependent bridge-cells are involved in the outgrowth of dorsal trunk branches toward their fusion partners.

Recent studies have shown that Bnl/dFGF is necessary for the primary tracheal branching, including the formation of the dorsal trunk (Sutherland et al. 1996; Metzger and Krasnow 1999). Therefore, we asked whether the absence of bridge-cells might interfere with bnl expression. We found that the expression pattern of $b n l$ was unaffected in $h b$ mutant embryos (Fig. $3 \mathrm{~J}, \mathrm{~K}$ ). Also, $h b$ expression in the bridge-cells was not affected in bnl mutant embryos and in embryos that lack the activity of breathless (bt1), which codes for the Bnl/ dFGF receptor (Fig. 3L; data not shown). Thus, bridge-cells do not interfere with the proper expression of Bnl/dFGF around the developing tracheal branches, and $h b$-expression in the bridge-cells is independent of Bnl/dFGF signaling.

Because localized Bnl/dFGF signaling is not necessary for dorsal trunk formation (Reichman-Fried et al. 1994; Lee et al. 1996; Sutherland et al. 1996), we asked whether the bridgecell mediates the proposed additional guidance mechanism for dorsal trunk branch outgrowth (Sutherland et al. 1996). By use of the Gal4/UAS-system (Brand and Perrimon 1993), we expressed Bnl/dFGF ectopically in tracheal cells to impede the spatial cues that are normally derived from the local arrangement of cell clusters expressing Bnl/dFGF. In contrast with wild-type embryos (Fig. 4A), embryos with ectopic expression of Bnl/dFGF develop complete dorsal trunk structures but lack the other primary branches (Fig. 4B). However, $h b^{F B}$ mutant embryos that express Bnl/dFGF ectopically had no signs of dorsal trunk branch outgrowth at all (Fig. 4C). These results indicate that the bridge-cell is necessary and essential for dorsal trunk formation, suggesting that this cell provides guidance cues specifically during the anterior-posterior dorsal trunk branch outgrowth. Thus, the bridge-cell, in combination with Bnl/dFGF signaling, directs outgrowth of the main tracheal tube and may mediate the proposed additional guidance mechanism.

To test the above inference, we expressed $h b$ ectopically via the Gal4/UAS-system (Brand and Perrimon 1993) in sensory organ precursor (SOP) cells in positions close to the bridge-cells. The outgrowing dorsal trunk anterior branches were seen in contact with the cells 

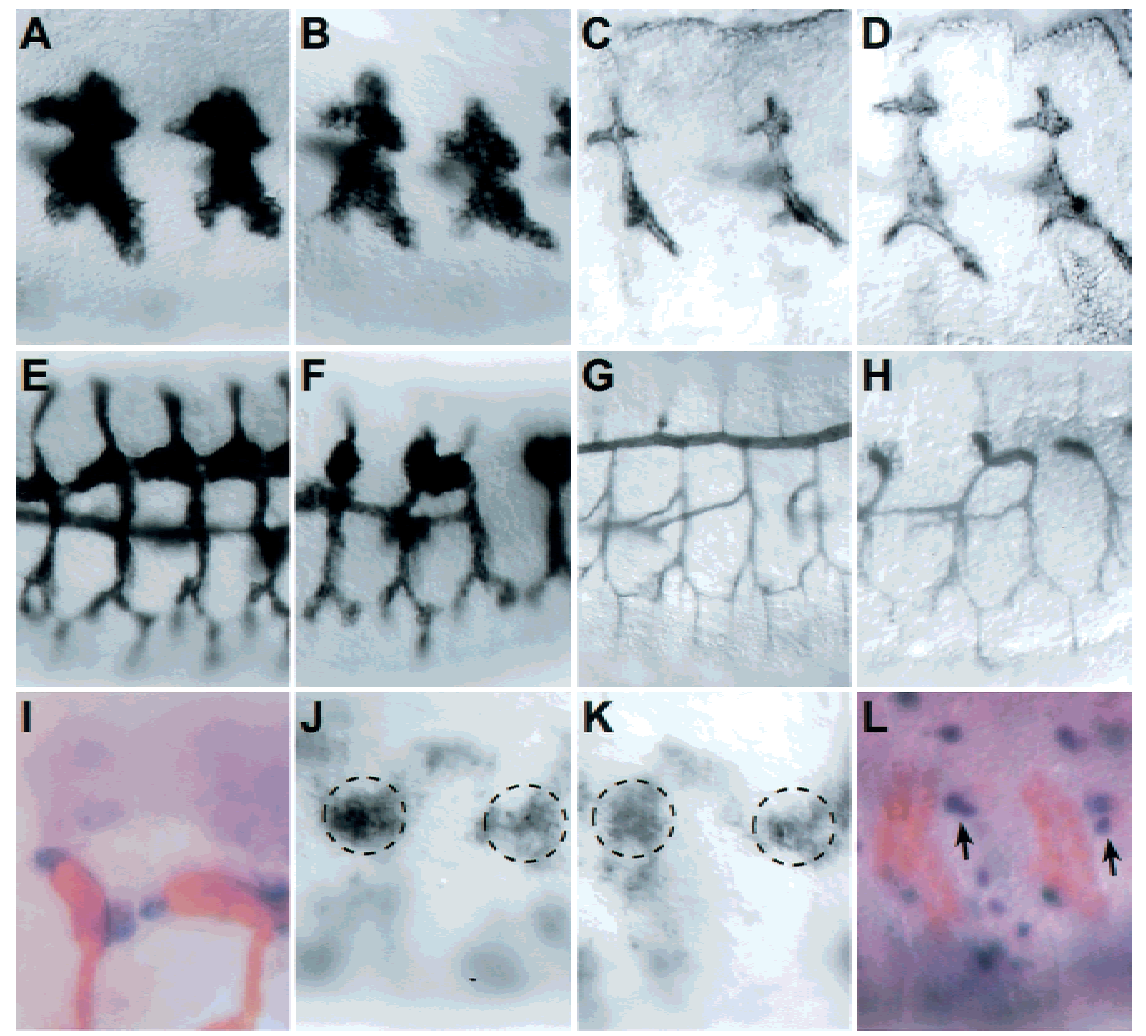

Figure 3. $h b$ expression in the bridge-cell is essential for directed outgrowth of dorsal trunk branches and does not interfere with dFGF signaling. Whole-mount in situ hybridization with a lacZ antisense RNA probe of wild-type $(A, E)$ and $h b^{F B}$ mutant $(B, F)$ embryos bearing the 1 -eve-1 chromosome at stage $12(A, B)$ and stage $15(E, F) .(C, D)$ Whole-mount antibody staining of a stage 12 wild-type $(C)$ and a $h b^{F B}$ mutant $(D)$ embryo with anti-Crumbs antibodies. $(G, H)$ Whole-mount antibody staining of a stage 15 wild-type $(G)$ and a $h b^{F B}$ mutant $(H)$ embryo with antibody $2 \mathrm{~A} 12$. This antibody specifically stains the tracheal lumen and reveals a normal lateral trunk but a lack of dorsal trunk formation in the $h b^{F B}$ mutant $(H)$. Note that the $h b^{9 Q}$ mutant embryos reveal an identical tracheal phenotype to that found in $h b^{F B}$ mutant embryos. (I) Wholemount antibody double staining of a stage $15 h b^{F B}$ mutant embryo bearing the G6 chromosome with $2 \mathrm{~A} 12$ (brown) and anti- $\beta$-galactosidase (blue) antibodies reveals esgdriven $\beta$-galactosidase expression in the dorsal trunk fusion cells of $h b^{F B}$ mutant embryos. $(J, K)$ Whole-mount in situ hybridization of a stage 12 wild-type $(J)$ and a $h b^{F B}$ mutant $(K)$ embryo using $b n l$ antisense RNA. The dynamic bnl expression pattern surrounding a single tracheal metamere (broken lines indicate bnl expression that guides dorsal trunk outgrowth) in either a wild-type $(J)$ or $h b^{F B}$ mutant $(K)$ embryo is identical. $(L)$ Whole-mount antibody double staining of a stage $12 \mathrm{bt} \mathrm{t}^{\mathrm{H} 2 \Delta 3}$ mutant embryo with anti- $\beta$-galactosidase (brown) and anti-Hb (blue) antibodies. The $b t t^{H 82 \Delta 3}$ mutant embryo reveals $\beta$-galactosidase expression in the tracheal nuclei (ReichmanFried et al. 1994) and $\mathrm{Hb}$ expression in the bridge-cells (arrows).

that ectopically express $h b$, even in the presence of the normal bridge-cells (Fig. 4D). As a consequence of the ectopic $h b$ expression, the dorsal trunk of the embryos show interruptions and abnormal bottleneck-like fusion points (Fig. 4E). Thus, hb expression in ectopic cells close to bridge-cells triggers a differentiation program that interferes with the directed outgrowth of the dorsal trunk branches suggesting that $h b$ activity is required not only for the viability but also for the identity of the bridge-cell. Whether the differentiation program involves local and short-range signals and/or provides a migration matrix by cell adhesion is unknown. How- ever, we prefer the hypothesis that the bridge-cell serves as an adhesion-dependent guiding post, as we observed tracheal cell extensions along the bridge-cell directly after the initial contact (Fig. 4F,G).

Our discovery of the bridge-cell and previous studies on Bnl/dFGF signaling provide a coherent model of how dorsal trunk formation may occur. After invagination of the tracheal placodes, budding of the tracheal metameres is triggered by localized $\mathrm{Bnl} /$ dFGF activity (Sutherland et al. 1996). This signal apparently does not always have the necessary precision on its own to guide the leading cells. The bridge-cell provides this precision by serving as a guidance post to properly position the budding dorsal trunk branches. The results also demonstrate an interplay of cells deriving from two different germ layers, mesoderm and ectoderm, which is necessary to establish the interconnected tubular tracheal network during embryogenesis. The identification of a key player in bridge-cell differentiation, namely the transcription factor $\mathrm{Hb}$, provides an entry point to unravel the molecular targets of $h b$. Their analysis may also contribute to gaining further insights into the function of the bridge-cells during tubular network formation, possibly in organisms other than Drosophila.

\section{Materials and methods}

\section{Materials}

We used the following antibodies: monoclonal antibody $2 \mathrm{~A} 12$ to stain tracheal lumen (DSHB, Iowa); anti- $\beta$-galactosidase antibody (Promega); anti-Hunchback antibody (gift from A. La Rosée, MPI, Göttingen); anti-Crumbs antibody (Tepass and Knust 1993); Alexa 488 or Alexa 546 goat antirabbit IgG or goat antimouse IgG (Molecular Probes); alkaline phosphatase-conjugated or biotinylated antirabbit IgG or antimouse IgG; biotinylated antimouse IgM (Vector Laboratories); anti-digoxigenin- and anti-fluorescein-AP, Fab fragments (Roche).

We used a number of alleles and fly strains: $U A S-h b$ flies (Wimmer et al. 2000); $h b^{F B}, h b^{9 Q}, d f r^{E 82}, t r h^{5 D 55}$, and $b t 1^{H 82 \Delta 3}$ were obtained from the Tübingen Stock Center. btl-Gal4 drives Gal4 expression ubiquitously in the tracheal system from stage 10 onward (Shiga et al. 1996). UAS-GFPNlacZ was used to detect nuclear $\beta$-galactosidase expression (Shiga et al. 1996). The lac $Z$ enhancer trap line 1 -eve-1 reveals P-element integration in the trh gene and was used to mark tracheal cells by cytoplasmic $\beta$-galactosidase (Perrimon et al. 1991). PO163 drives Gal4 in a subset of peripheral nervous system precursor cells (Janning 1997). UAS-P35 was provided by H. Steller (MIT, Cambridge). The P-element of the lacZ enhancer trap line G6 is integrated in the esg gene and marks dorsal trunk homotip cell nuclei (Whiteley et al. 1992). We also used actin-Gal4 and twi-Gal4 flies (Greig and Akam 1993). 
A

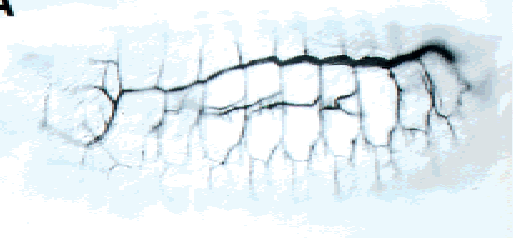

B

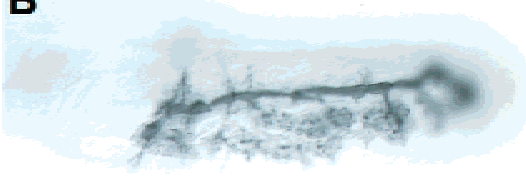

C

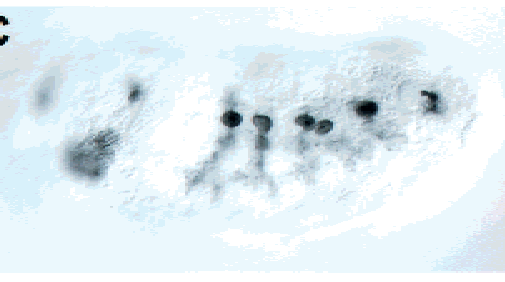

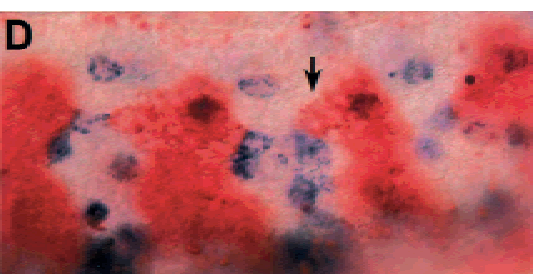

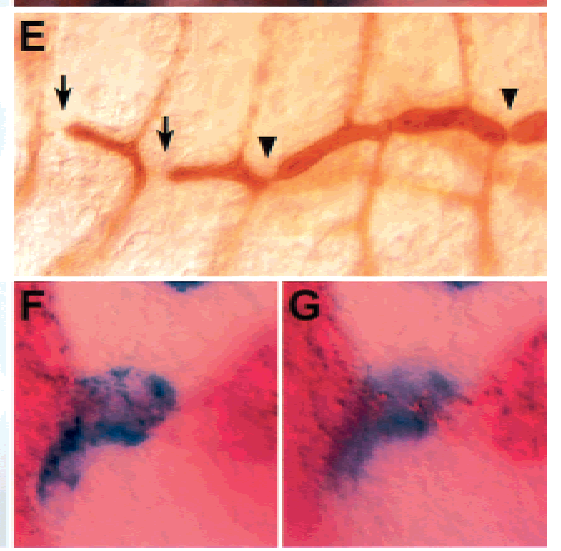

Figure 4. The bridge-cell is necessary for dorsal trunk branch outgrowth. $(A-C)$ Whole-mount antibody $2 \mathrm{~A} 12$ staining of a stage 15 wild-type embryo $(A)$, an embryo bearing $U A S-b n l$ and $b t l-G a l 4(B)$, and a $h b^{F B}$ mutant embryo bearing $U A S-b n l$ and $b t 1-G a 14(C)$. Note that the tracheal phenotype of amorphic bnl ${ }^{P 1}$ mutant embryos bearing $U A S-b n l$ and $b t l-G a l 4$ is indistinguishable from the phenotype shown in $B$. The lack of tracheal metameres in $h b^{F B}$ mutant embryos is caused by the lack of segmental anlagen in such embryos (Lehmann 1985; Tautz et al. 1987). (D) Wholemount in situ double-hybridization of a stage 12 embryo bearing UAS- hb, PO163Gal4 and the 1-eve-1 chromosome with lacZ (red) and $h b$ (blue) antisense RNA probes. PO163-Gal4 (Janning 1997) drives hb expression in SOP cells. (Arrow) Outgrowing dorsal trunk anterior branch that attaches to a $h b$ expressing cell but lacks contact with the bridge-cell. (E) Whole-mount antibody staining of a stage 15 embryo bearing UAS-hb and PO163-Gal4 with antibody 2A12. Ectopic hb expression causes bottleneck-like lumen formation (arrowheads) and a lack of dorsal trunk interconnection (arrow). $(F, G)$ Whole-mount in situ double hybridization of a stage 12 embryo bearing the 1 -eve- 1 chromosome with lac $Z$ (red) and $h b$ (blue) antisense RNA probes. The same image is shown focused on the bridge-cell $(F)$ and the tracheal cell extensions $(G)$, respectively.

\section{TUNEL assay}

TUNEL analysis of embryos was done by RNA in situ hybridization with the following modifications: After the second fixation step, the embryos were washed with TUNEL reaction mixture (In Situ Cell Death Detection Kit, AP; Roche) and incubated with $100 \mu \mathrm{l}$ of TUNEL reaction mixture for $120 \mathrm{~min}$ at $37^{\circ} \mathrm{C}$; the embryos were washed with PBT and incubated with anti-fluorescein antibody (Roche) for $12 \mathrm{hr}$ at $4^{\circ} \mathrm{C}$.

\section{Immunostainings and in situ hybridizations}

RNA in situ hybridizations and immunostainings to whole-mount embryos were performed as described (Goldstein and Fryberg 1994). The RNA probes used in our experiments were derived from bnl (Sutherland et al. 1996), stg (Edgar and O'Farrell 1990), lacZ, and sal (Kühnlein et al. 1994). Immunostained embryos were viewed with a Zeiss Axiophot microscope. Embryos stained with fluorescent antibodies were analyzed by laser scanning microscopy as described (Kühnlein and Schuh 1996).

\section{Acknowledgments}

We are grateful to M. González-Gaitán for initiation of the project. Special thanks go to $\mathrm{H}$. Jäckle for providing a stimulating environment and critical reading of the manuscript. We thank M.A. Krasnow, A. La Rosée, C. Samakovlis, H. Steller, and E. Wimmer for antibodies, cDNAs and fly stocks. We also thank M. Affolter, R.P. Kühnlein, C. Krause and E. Wimmer for critical comments on the manuscript. This work was supported by the Max-Planck-Society (MPIbpc Abt. 170) and the Deutsche Forschungsgemeinschaft (SFB 271).

The publication costs of this article were defrayed in part by payment of page charges. This article must therefore be hereby marked "advertisement" in accordance with 18 USC section 1734 solely to indicate this fact.

\section{References}

Brand, A.H. and Perrimon, N. 1993. Targeted gene expression as a means of altering cell fates and generating dominant phenotypes. Development 118: $401-415$.

Edgar, B.A. and O'Farrell, P.H. 1990. The three postblastodermal cell cycles of Drosophila embryogenesis are regulated in G2 by String. Cell 62: 469-480.

Goldstein, L.S.B. and Fryberg, E.A. 1994. Drosophila melanogaster: Practical uses in cell and molecular biology. Methods Cell Biol. 44: 446-485.

Greig, S. and Akam, M. 1993. Homeotic genes autonomously specify one aspect of pattern in the Drosophila mesoderm. Nature 362: 630-632.

Hay, B.A., Wolff, T., and Rubin, G.M. 1994. Expression of baculovirus P35 prevents cell death in Drosophila. Development 120: 2121-2129.

Hoch, M., Seifert, E., and Jäckle, H. 1991. Gene expression mediated by cis-acting sequences of the Krüppel gene in response to the Drosophila morphogens bicoid and hunchback. EMBO J. 10: 2267-2278.

Hogan, B.L.M., Grindley, J., Bellusci, S., Dunn, N.R., Emoto, H., and Itoh, N. 1997. Branching morphogenesis of the lung: New models for a classical problem. Cold Spring Harbor Symp. Quant. Biol. 62: $249-256$.

Hülskamp, M. 1991. Funktionelle Analyse des Segmentierungsgens hunchback von Drosophila melanogaster. Thesis, University of Tübingen, Germany.

Isaac, D.D. and Andrew, D.J. 1996. Tubulogenesis in Drosophila: A requirement for the trachealess gene product. Genes \& Dev. 10: 103-117.

Janning, W. 1997. Fly View, a Drosophila image database, and other Drosophila databases. Cell Dev. Biol. 8: 469-475.

Kühnlein, R.P. and Schuh, R. 1996. Dual function of the region specific homeotic gene spalt during Drosophila tracheal system development. Development 122: 22152223.

Kühnlein, R.P., Frommer, G., Friedrich, M., Gonzalez-Gaitan, M., Weber, A., Wagner-Bernholz, J.F., Gehring, W.J., Jäckle, H., and Schuh, R. 1994. spalt encodes an evolutionarily conserved zinc finger protein of novel structure which provides homeotic gene function in the head and tail region of the Drosophila embryo. EMBO J. 13: 168-179.

Lee, T., Hacohen, N., Krasnow, M., and Montell, D.J. 1996. Regulated Breathless receptor tyrosine kinase activity required to pattern cell migration and branching in the Drosophila tracheal system. Genes \& Dev. 10: 2912-2921.

Lehmann, R. $1985 . \quad$ Regionsspezifische Segmentierungsmutanten bei Drosophila melanogaster Meigen. Thesis, University of Tübingen, Germany.

Manning, G. and Krasnow, M.A. 1993. Development of the Drosophila tracheal system. In The development of Drosophila melanogaster (ed. M. Bate and A. Martinez Arias), pp. 609-685. Cold Spring Harbor Laboratory Press, Cold Spring Harbor, NY.

Metzger, R.J. and Krasnow, M.A. 1999. Genetic control of branching morphogenesis. Science 284: 1635-1639.

Perrimon, N., Noll, E., McCall, K., and Brand, A. 1991. Generating lineage-specific markers to study Drosophila development. Dev. Genet. 12: $238-252$.

Reichman-Fried, M., Dickson, B., Hafen, E. and Shilo, B.-Z. 1994. Eluci- 
dation of the role of breathless, a Drosophila FGF receptor homolog, in tracheal cell migration. Genes \& Dev. 8: 428-439.

Risau, W. 1997. Mechanism of angiogenesis. Nature 386: 671-674.

Samakovlis, C., Hacohen, N., Manning, G., Sutherland, D.C., Guillemin, K., and Krasnow, M.A. 1996. Development of the Drosophila tracheal system occurs by a series of morphologically distinct but genetically coupled branching events. Development 122: 1395-1407.

Shiga, Y., Tanaka-Matakatsu, M., and Hayashi, S. 1996. A nuclear GFP/ $\beta$-galactosidase fusion protein as a marker for morphogenesis in living Drosophila. Dev. Growth Differ. 38: 99-106.

Sutherland, D., Samakovlis, C., and Krasnow, M.A. 1996. branchless encodes a Drosophila FGF homolog that controls tracheal cell migration and the pattern of branching. Cell 87: 1091-1101.

Tautz, D., Lehmann, R., Schnürch, H., Schuh, R., Seifert, E., Kienlin, A., Jones, K., and Jäckle, H. 1987. Finger protein of novel structure encoded by hunchback, a second member of the gap class of Drosophila segmentation genes. Nature 327: 383-389.

Tepass, U. and Knust, E. 1993. Crumbs and stardust act in a genetic pathway that controls the organization of epithelia in Drosophila melanogaster. Dev. Biol. 159: 311-326.

Whiteley, M., Noguchi, P.D., Sensabaugh, S.M., Odenwald, W.F., and Kassis, J.A. 1992. The Drosophila gene escargot encodes a zinc finger motif found in snail-related genes. Mech. Dev. 36: 117-127.

Wilk, R., Weizman, I., and Shilo, B.-Z. 1996. trachealess encodes a bHLHPAS protein that is an inducer of tracheal cell fates in Drosophila. Genes \& Dev. 10: 93-102.

Wimmer, E.A., Carleton, A., Harjes, P., Turner, T., and Desplan, C. 2000. bicoid-independent formation of thoracic segments in Drosophila. Science 278: 2476-2479. 


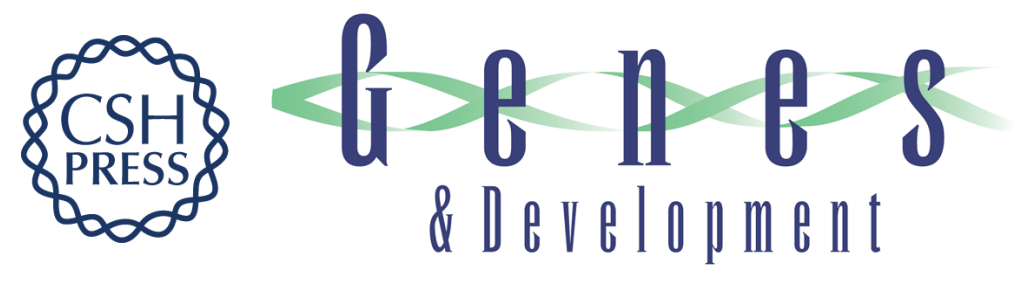

\section{Single mesodermal cells guide outgrowth of ectodermal tubular structures in Drosophila}

Christian Wolf and Reinhard Schuh

Genes Dev. 2000, 14:

Access the most recent version at doi:10.1101/gad.180900

References This article cites 21 articles, 10 of which can be accessed free at: http://genesdev.cshlp.org/content/14/17/2140.full.html\#ref-list-1

License

Email Alerting Receive free email alerts when new articles cite this article - sign up in the box at the top Service right corner of the article or click here.

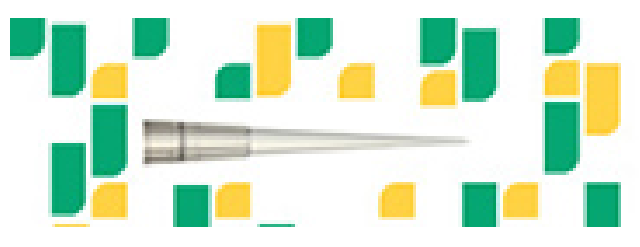

Focused on your science. 